\title{
Rhinolith misdiagnosed as allergic rhinitis: case report
}

Qais Aljfout, Mohammad Saraireh, Abdullah Maita

Royal Medical Services RMS, Amman, Jordan

\section{Type of article: Case report}

\begin{abstract}
Foreign body neglected in the nasal cavity for many years leads to the formation of a rhinolith, which gradually increases in size. Nasal obstruction and persistent foul smelling nasal discharge usually are the main presenting symptoms, although some might be silent. This paper presents and discuss a case of 19-year-old female patient whose main complaint was nasal obstruction for many years and treated as allergic rhinitis. Diagnosis was confirmed with computed tomography scan, and it was removed endoscopically without complications. We think that proper examination, which includes endoscopic evaluation, should be done to reach the diagnosis. A computed tomography scan confirmed the diagnosis and helped in planning the best treatment option.
\end{abstract}

Keywords: Allergic rhinitis, foreign body, nose, rhinolith

\section{Introduction}

Rhinolith result from a neglected foreign body inserted into the nasal cavity. Over several years, calcium, magnesium, iron, and phosphorus salts accumulate around this foreign body, which acts as a central core, with subsequent increase in its size (1). Initially, the patient might be asymptomatic (2). Later, the patient usually starts to complain of symptoms due to the inflammatory and infective responses that lead to purulent nasal discharge and unilateral obstruction. At this stage, it might be diagnosed as infective rhinosinusitis (3), but the unilaterality of symptoms should draw attention toward the possibility of a foreign body or rhinolith $(4,5)$.

\section{Case presentation}

\subsection{Case history}

A 19-year-old female patient, previously not known to have medical illness, presented to the ENT clinic at Prince Ali Hospital in Karak City, Jordan, in July 2015, complaining of nasal obstruction that was persistent and more on the left side. This was associated with intermittent purulent left-sided nasal discharge for many years. The patient had no history of dental treatment and had been evaluated many times by general practitioners, family physicians, and even otorhinolaryngologists without significant benefits. Review of her medical records revealed that she was diagnosed as allergic rhinitis and treated with topical steroids, oral antihistamines, local decongestant and even oral antibiotics without improvement. Despite the fact that the patient did not improve on the prescribed treatment and her complaints continued, further evaluations, such as endoscopic or even radiological examinations, were not done.

\subsection{Clinical and endoscopic evaluation}

Anterior rhinoscopy in the clinic showed that the patient had complete obstruction of left side of the nasal cavity with purulent discharge, hypertrophy of both inferior turbinates, and congested nasal mucosa. Rigid endoscopic examination revealed severe mucosal edema with purulent discharge; posterior choana were not observed on the left side.

\subsection{Radiological evaluation}

So, the decision was made to perform a computed tomography scan of the nose and paranasal sinuses for better evaluation. A few days later, the patient was re-evaluated in the clinic, and her sinonasal computed tomography scan

\section{Corresponding author:}

Qais Aljfout, Royal Medical Services RMS, Amman, Jordan. Tel: +962772256809, E-mail: qaisj@yahoo.com Received: December 30, 2015, Accepted: February 03, 2016, Published: February 2016 iThenticate screening: January 30, 2016, English editing: February 04, 2016, Quality control: February 08, 2016 (C) 2016 The Authors. This is an open access article under the terms of the Creative Commons Attribution-NonCommercialNoDerivs License, which permits use and distribution in any medium, provided the original work is properly cited, the use is non-commercial and no modifications or adaptations are made. 
revealed soft tissue density with areas of calcification on the left side of the nasal cavity with complete obstruction of the choana and mucosal thickening of the left maxillary sinus in the absence of any bony destruction (Figure 1).

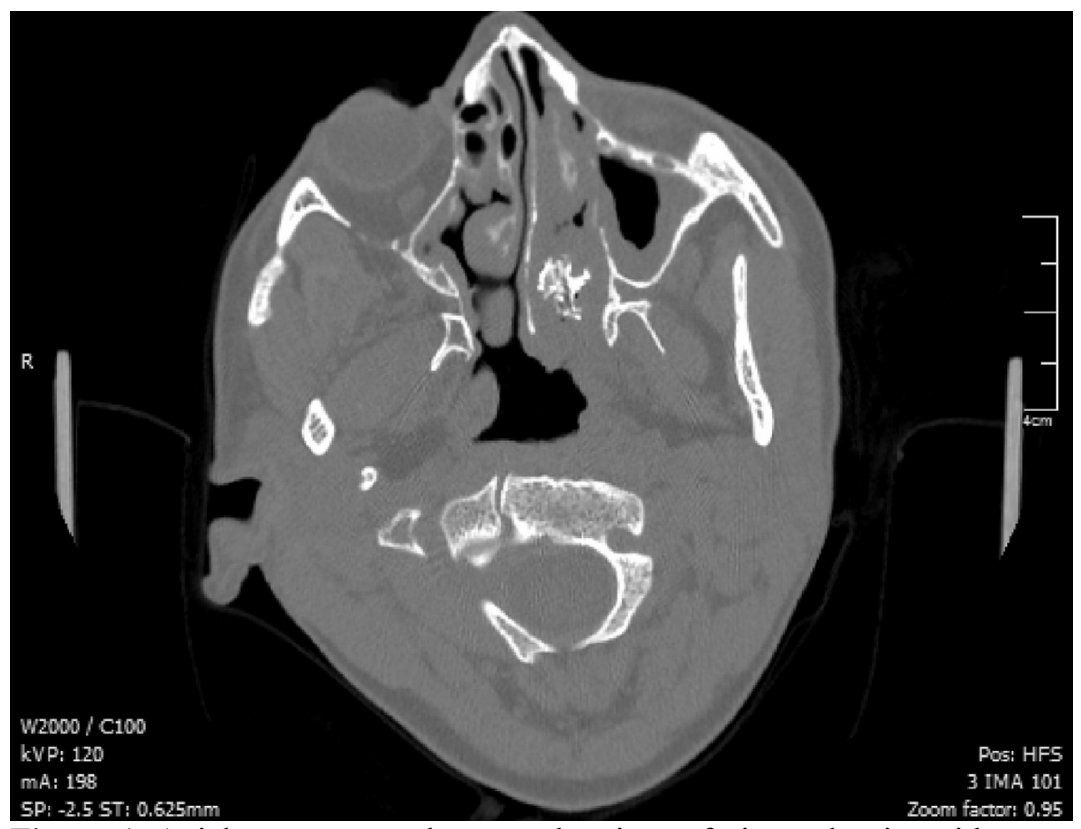

Figure 1. Axial cut tomography scan showing soft tissue density with areas of calcifications in the left nasal cavity, mucosal thickening of left maxillary sinus, and complete obstruction of left choana

\subsection{Diagnosis, management, and follow up}

Our initial impression was a rhinolith. So, the patient consented to endoscopic sinonasal. A few days later, the patient underwent endoscopic removal under general anesthesia. Operative findings were soft tissue mass with concrete-like calcifications around a plastic foreign body and complete obstruction of the left posterior choana (Figures 2-4). The patient was discharged the next day on oral antibiotics, a local decongestant, and local steroids. One week later at follow up, the patient had complete resolution of her symptoms, and she was extremely satisfied.

\subsection{Ethics of case report}

Informed consent was obtained directly and in writing from our patient, and, also, the ethics committee of our institution approved this study and report (Ref. no. 7/2015).

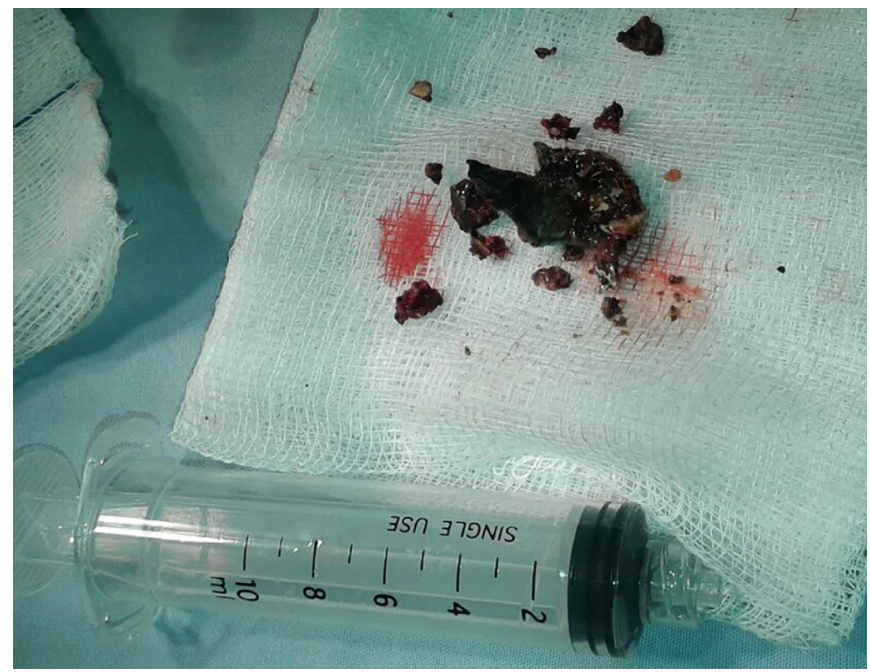

Figure 2. Foreign body removed in the operating room 


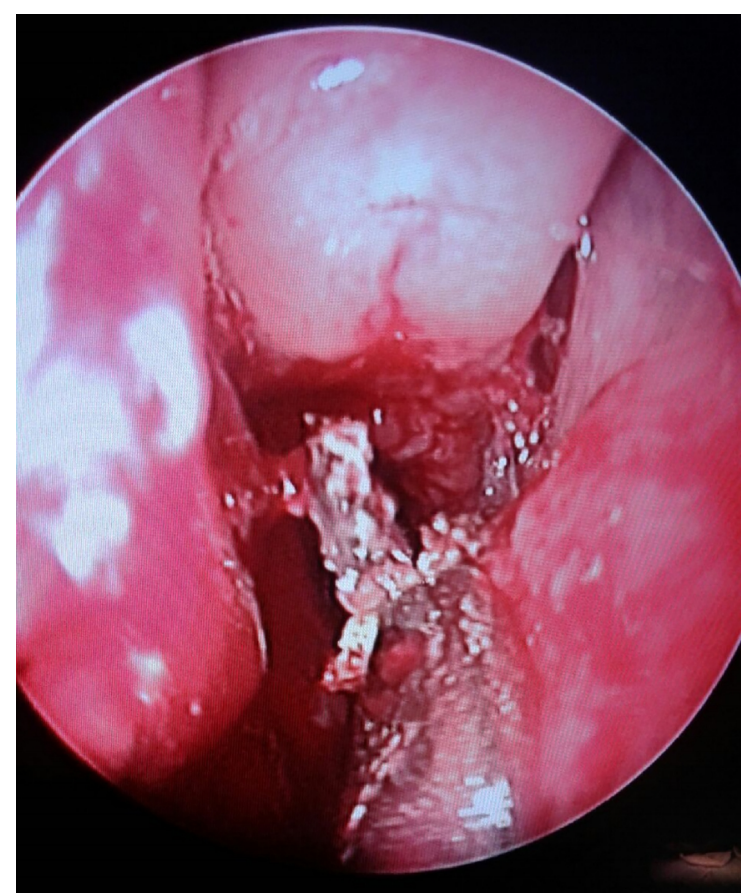

Figure 3. Endoscopic view of concrete-like material removed during surgery

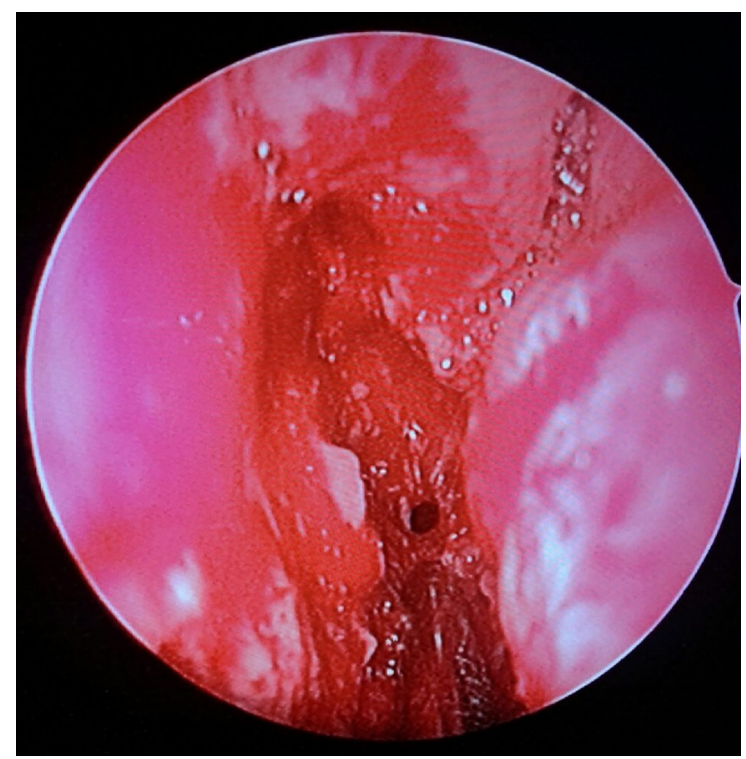

Figure 4. Endoscopic view during surgery showing complete obstruction of the left choana

\section{Discussion}

\subsection{History and clinical presentation}

Patients with rhinolith usually complain of unilateral purulent rhinorrhea accompanied by ipsilateral nasal obstruction $(3,6,7)$. Other symptoms include headache, fetor, epistaxis, and, in rare cases, symptoms or signs of involvement or erosion into neighbor structures, such as the epiphora or oroanasal fistula $(2,6)$. In some patients, rhinoliths are discovered incidentally.

\subsection{Clinical examination}

In all patients with sinonasal complaints, examination should include anterior rhinoscopy with good illumination and rigid endoscopy to evaluate both sides and proper visualization of intranasal structures and post-nasal space. 


\subsection{Radiological evaluation}

Plain sinuses X-ray and sinonasal CT scan confirmed the diagnosis through the presence of calcified concretions in the nasal cavity, in addition to the advantage of planning the best surgical approach. Computed tomography of the paranasal sinuses can help to determine the size, the extent of the rhinolith, and reveal its effect on the sinonasal cavity, which may also require treatment (4). In our case, we think that low index of suspicion and incomplete endoscopic and radiological evaluation led to the delay in diagnosis.

\subsection{Pathogenesis and differential diagnosis}

Although the pathogenesis of rhinolith is unclear (2), it is estimated that around 15 years is the time required for it to form. The differential diagnosis includes calcified nasal polyps, osteoma osteosarcoma, chondrosarcoma, dermoid odontoma, impacted teeth, and syphilitic or tubeculous calcification (5, 7-9). In our case, we think that delays in referral and a busy clinic that evaluate referral had led to the delay in the diagnosis.

\subsection{Management}

Treatment of rhinolith is removal, which might be through the nostrils or by using a rigid endoscope, which is better and is the most frequently-used method. Lateral rhinotomy can be performed in rare complicated cases where the open route is necessary (4).

\section{Conclusions}

Diagnosis of a rhinolith requires a high index of suspicion based on the patient's symptoms, unilateral complaint, physical examination, and endoscopic evaluation. Rhinolith should always be considered in the differential diagnosis in teenagers and adults who present with unilateral nasal obstruction and foul-smelling unilateral nasal discharge. Proper examination, which includes endoscopic evaluation, should be done to reach the diagnosis. A computed tomography scan can confirm the diagnosis and help in planning the best treatment option.

\section{Acknowledgments:}

This paper was extracted from the authors' clinical work, and it received no specific grant from the government or any other funding agency.

\section{Conflict of Interest:}

There is no conflict of interest to be declared.

\section{Authors' contributions:}

All authors contributed to this project and article equally. All authors read and approved the final manuscript.

\section{References}

1) Varley EW. Rhinolith: An incidental finding. Br J Oral Surg. 1964;2(1):40-3. DOI: 10.1016/S0007117X(64)80007-X, PMID: 5212879

2) Carder HM, Hill JJ. Asymptomatic rhinolith: A brief review of the literature and case report. Laryngoscope. 1966;76(3):524-30. DOI: 10.1288/00005537-196603000-00009

3) Royal SA, Gardner RE. Rhinolithiasis: An unusual pediatric nasal mass. PediatrRadiol. 1966;28(1):54-5. DOI: $10.1007 / \mathrm{s} 002470050292$, PMid: 9426275

4) Hadi U, Ghossaini S, Zaytoun G. Rhinolithiasis: a forgotten entity. Otolaryngol Head Neck Surg 2002;126:48-51. DOI: 10.1067/mhn.2002.121018, PMID: 11821765

5) Singh RK, Varshney S, Bist SS, Gupta N, Bhatia R, Kishor S A case of rhinolithiasis. Online J Health Allied Sci, 2008;7(2):7.

6) Dib GC, Tangerina PR, Abreu EC, et al. Rhinolithiasis as cause of oronasal fistula. Rev Bras Otorrinolaringol 2005;71:101-3. DOI: 10.1590/S0034-72992005000100019, PMID: 16446901

7) Sumbullu MA, Tozoglu U, Yoruk O, Yilmaz AB, Ucuncu H. Rhinolithiasis: the importance of flatpanel detector-based cone beam computed tomography in diagnosis andtreatment. Oral Surg Oral Med Oral Pathol Oral RadiolEndod 2009;107:e65-7. doi: 10.1016/j.tripleo.2009.02.029. PMID: 19464647

8) Senkal HA, Süslü AE, Ünal ÖF. A rare cause of rhinolithiasis: ectopic tooth.Int J Pediatr Otorhinolaryngol Extra 2006;1:249-52. DOI: 10.1016/j.pedex.2006.07.004

9) Dhingra S, Gulati A. Teeth in Rare Locations with Rare Complications: An Overview. Indian J Otolaryngol Head Neck Surg. 2015 Dec;67(4):438-43. doi: 10.1007/s12070-015-0878-8 PMID: 26693467 